\title{
Significance of physicochemical factors in the transmission of Escherichia coli and chloride
}

\author{
Sahar Akhavan ${ }^{1}$, Soheila Ebrahimi ${ }^{*}$, Maryam Navabian ${ }^{2}$, Mahmoud Shabanpour ${ }^{3}$, Ali Mojtahedii ${ }^{4}$, Alireza \\ Movahedi Naeini ${ }^{1}$ \\ ${ }^{1}$ Department of Soil Sciences, Soil and Water Engineering School, Gorgan University of Agricultural Sciences and Natural Resources, \\ Gorgan, Iran. \\ ${ }^{2}$ Department of Water Engineering, School of Agriculture, University of Guilan, Rasht, Iran \\ ${ }^{3}$ Department of Soil Science, School of Agriculture, University of Guilan, Rasht, Iran \\ ${ }^{4}$ Department of Microbiology, School of Medicine, Guilan University of Medical Sciences, Rasht, Iran
}

\begin{abstract}
Background: Organic manures are the source of many pathogenic bacteria which could be dangerous for human health. Bacterial transmission and retention in soil is important for processes ranging from contaminant degradation during in situ bioremediation to transport of pathogenic bacteria into groundwater.

Methods: The aim of this study was to evaluate the transport of Escherichia coli and chloride $(\mathrm{Cl})$ in the soil saturation conditions, considering the importance of preferential flow using synthetic macrospores (different diameters of macrospores including 0,1 and $2 \mathrm{~cm}$ ) and HYDRUS-2D model. Also, the effect of different salinity levels of water (including electrical conductivity of 1,2 and $4 \mathrm{dSm}^{-1}$ ) on the transmission of $E$. coli was investigated. The preferential flow system was prepared and designed using two sand sizes including fine sand and coarse sands in the columns.

Results: The results showed that the retention of $E$. coli increased with the ionic strength of the solution, while the effect of $E$. coli in the fine sand was greater than that of the coarse sand. This bacterial transfer behavior was well described by numerical simulations. The importance of preferential flow in bacterial transfer showed that it increases at higher ionic strength, even if overall transmission is reduced. Although the bacterial transmission is facilitated in salinity, the results of this study showed that with increase of ionic strength of the soil solution, the amount of bacterial purification was increased that could be effective in controlling groundwater contamination with saline water management.

Conclusion: According to the results, with increase of ionic strength of the soil solution, the amount of bacterial purification was increased that could be effective in controlling groundwater contamination with saline water management, so that the least transition has taken place and the conditions for the use of unconventional water sources were also created, without the environmental problem of the risk of groundwater pollution.

Keywords: Escherichia coli, Soil, Water pollution

Citation: Akhavan S, Ebrahimi S, Navabian M, Shabanpour M, Mojtahedi A, Movahedi Naeini A. Significance of physicochemical factors in the transmission of Escherichia coli and chloride. Environmental Health Engineering and Management Journal 2018; 5(2): 115-122. doi: 10.15171/ EHEM.2018.16.
\end{abstract}

Article History:

Received: 21 April 2018

Accepted: 29 May 2018

ePublished: 15 June 2018

\section{Introduction}

Fertilizers are the source of some pathogenic bacteria that are harmful to human health and environment. Reaching this bio-pollutant to water resources is mainly due to human activities such as household, municipal and hospital wastes, waste disposal sites, wastewater wells, animal waste and animal fertilizers (1). Soil filtration removes or degrades bacterial pathogen in water as it passes through on its way to groundwater (2). But, macropores of soil increase the transmission of bacteria.
Several studies have shown that bacteria could transport easily within the preferential flow direction (3-10). The transfer of bacteria in the soil is controlled by several mechanisms including advection, dispersion, attachment, detachment, inactivation (die-off), and straining $(11,12)$. The inactivation of the bacteria is affected by various factors such as temperature, light, $\mathrm{pH}$, toxic substances, oxygen, protozoa and antagonist (13).

Today, the use of alternative sources, especially unconventional water sources such as drainage waters from 
farms, saline water and surface and underground waters, has been seriously increased due to the growing restrictions of freshwater resources and consequent reduction soil fertility and quality. Although the application of saline water shows a significant difference compared with nonsaline water conditions, but there are some options for the continuity and stability of agricultural activities, in order to provide a suitable bed for their sustainable consumption (14). Salinity is one of the important stressors for microorganisms. It decreases respiration, carbon dioxide levels, enzymatic activity and microbial biomass (15). Several studies have investigated the effects of saline water on the degradation or improvement of physical, chemical and biological properties of soils, with different and sometimes contradictory results. Ionic strength, electrolyte ion balance and soluble $\mathrm{pH}$ conditions are the three main factors affecting the reaction of the bacteria to the sand surface and their effect on bacterial retention has been investigated by many scholars, although the results of some studies were completely contradictory. For example, in theory, with increase of ionic strength, the maintenance of bacteria on the negative charge of subsurface deposits increases, because due to the compression of the double layer of compression electrostatic balance, equilibrium is established between superficial load of bacteria and sediment. However, different results were reported by Kim et al (16). They did not find any effect on ionic strength except at high $\mathrm{pH}$ on the retention of microorganisms. The electrolyte with bivalent cation can play the role of a bridge, and reacting with the surface load of the cell, keeps more bacteria in the porous medium, but the effect of negative loads of the multivalent ions is contradictory to the transmission or retention of the bacterium or virus under subsurface conditions. The factors influencing the reaction of the bacteria with the surface of the sand, are surface load change and hydrophobic properties (10). Also, surface absorption affects cell surface load, hydrophobicity, size and lipopolysaccharide surface structure (LPS) of the outer membrane of the cell wall of $E$. coli. It is due to this fact that liposaccharide of $E$. coli is the main factor in its absorption onto the mineral surfaces, absorption of metal ions and microbial stimuli, and sediment reactions and dissolution. Liposaccharide contains a phosphoric oligosaccharide hydrophobic fat and polysaccharide, which due to its low hydrophobic contact angle, leads to weak adhesion of E. coli (17). Also, various studies have shown that the main reason for the transfer of bacteria to undisturbed soils is preferential flows due to the continuity of coarse pores and cracks in the soil. During the transfer of bacteria, the presence of macropores and bio-pores allows fertilizer wastewater and microorganisms to quickly pass the soil matrix and reach deeper soils and possibly to subsurface drainage systems (18).

Measuring the parameters of soil and water is costly and time consuming. The prediction and simulation of these parameters using modeling, reduces the cost of water management (19). The HYDRUS-2D software has been developed to simulate the two-dimensional movement of water, heat and solvents in a porous medium and different humidity conditions. In this model, Richard's equations and flux-diffusion are used to explain the movement of water and solutes (20). Safadost et al examined the role of restoration of soil structure with physical weathering by testing columns for the transmission of E. coli and bromide. Observational data were analyzed using Mobile-Immobile (MIM) model by HYDRUS-2D software. The model estimates well the concentrations of wastewater. The results showed that the absorption coefficients of bacteria increased with clay content. The first peak in the breakthrough curve was observed for the weathered columns of the soil, which was attributed to the increase of the connection of pores with weathering and the presence of preferential flow. The balanced and symmetrical shape of the breakthrough curves of the soil columns showed that leaching mainly occurred through the matrix flow (21). Wang et al accurately described the precise transmission of $E$. coli in the column with the status and length of different synthetic macropores at two levels of ionic strength ( 1 and $20 \mathrm{mM} \mathrm{NaCl}$ ) using the dual-permeability flow model in HYDRUS software, by optimizing the absorption parameters of the bacterium (10). The results showed that with decrease of macropores length, the apparent saturation hydraulic conductivity in the macroporous range was reduced. Also, the length of synthetic macropores greatly influenced the preferential transmission of $E$. coli, especially in high ionic strength conditions. In low ionic strength, a wider transport in the preferred pathway and an earlier time to reach $E$. coli than bromide was observed as a result of the size limitation (18). In another study, Unc et al, using modeling with HYDRUS, reported that the estimation of the migration rate of bacteria in the soil profile was consistent with the major hypothesis of bacterial transmission from macropores. The transfer rate of the bacteria was faster than that of water transfer in the soil pores. Suspended bacteria pass faster through the larger diameter of the pores and water in the pores (9). In this research, the transmission and retention of $E$. coli as an indicator of groundwater contamination in soil saturation conditions with regard to the importance of preferential flow were investigated using synthetic macroproes and simulated using HYDRUS-2D model. Also, the effect of different levels of salinity on the transmission of E. coli was investigated. The main aim of this research was to evaluate the transmission status of contaminant index (E. coli) in the presence of preferential flow with different diameters and different levels of water salinity in the experimental columns. In addition, the microbiological contaminant retention was evaluated at various soil depths.

Methods 


\section{Bacteria}

Escherichia coli is the most common coliform of the cow manure that is considered as a bio-indicator of underground water pollution in the research. Features such as easy counting, hydrophilic and strong negative load of E. coli make it an indicator of underground fecal contamination assessment, especially in developing countries, with respect to the limited laboratory resources. E. coli is a gram-negative bacterium, rod shaped, 1.1$1.5 \mu \mathrm{m} \times 2-6 \mu \mathrm{m}$, single or pair and is a member of Enterobacteriaceae family (17).

\section{Transport experiment}

Preferential flow experiments were carried out in PVC containers with specific lengths and inner diameters (20 and $10 \mathrm{~cm}$, respectively). After measuring some of the primary soil properties (Table 1), the preferential flow system was prepared and designed using two sand types including fine sand and coarse sands in the columns. To prepare the soil columns, first, about one third of the height of the column was filled with distilled water (autoclaved) and a plastic tube with a diameter of $30 \mathrm{~cm}$ with a desired diameter $(1$ and $2 \mathrm{~cm}$ ) was placed in the center of the column. The fine sand was gradually added to the column matrix (outside of the plastic tube). Then, the extra water in the plastic tube was drained from the bottom. Afterwards, the tube was carefully drawn out of the column without disturbance around the sand structure, leaving a hole with a diameter of $2 \mathrm{~cm}$ in the center of the column. At this stage, the hole was filled up to a depth of $20 \mathrm{~cm}$ with coarse sand using a funnel to create the macropore structure of the desired preferential flow.

Before the bacterial transfer test, two pore volumes (PV) of $\mathrm{NaCl}$ solution (saline treatment) were selected and added to the sterilized columns using sterilized physiology serum and allowed the sand to reach a balance state with the solution (phase 0). Bacterial transfer experiments were carried out in two phases with boundary conditions and flow velocity, similar to phase 0 . First, a pulse of bacterial suspension was added to the column at a constant velocity (phase 1). Then, an $\mathrm{NaCl}$ solution in the column was added with a flow rate and ionic strength similar to those in phase 1 until the concentration of the microbial wastewater returned to the initial amount (phase 2). Bacterial suspension was sprayed uniformly at the top of the sterile soil column along the flame using a sterile syringe. The bacterial suspension was prepared by McFarland Turbidity Standard by mixing $1.175 \%$ barium chloride dihydrate $(0.048 \mathrm{M})$, with $9.95 \mathrm{~mL}$ of $1 \%$ sulfuric acid $(0.36 \mathrm{~N})$. Soil columns were washed for one hour and wastewater samples were collected from the bottom of the column at times of $0,1,2,3,5,7,10,12,15,20,25,35,40$, $45,50,60 \mathrm{~min}$. The experiment was performed with three replications for each treatment. After experiment, bacterial and chlorine concentrations were analyzed. The drained bacterial suspensions were prepared with dilutions of $10^{-1}$, $10^{-2}$ and $10^{-3}$. After dilution of the samples, $0.1 \mathrm{ml}$ of the diluted solution was cultured in eosin methylene blue agar (EMB) plates. The bacterial concentrations in the effluent were estimated by the number of $E$. coli colonies in $\mathrm{EMB}$ agar after 24 hours incubation at $37^{\circ} \mathrm{C}$, then, the concentration of the bacteria in the drained water was calculated and expressed with the unit of colony in milliliters (CFU/mL) (22).

In order to measure the concentration of bacteria in the soil profile, after the bacterial transfer experiment, the soil column was divided into three layers. The samples were taken from three depths. Then, $1 \mathrm{~g}$ of each sample was added to a $15 \mathrm{~mm}$ centrifuge tube with a $9 \mathrm{~mL}$ solution of $0.2 \%$ sodium hexametaphosphate. For isolation of the bacteria in the liquid phase from the solid phase, each sample was mixed in a vortex mixer for 15 minutes. To determine the concentration of bacteria in the uppermost solution, live counting method was used (22). The bacterial counting in the soil profile was done by measuring the concentration of bacteria in the wastewater.

To measure the chloride concentration of each sample, the drained water was measured by titration with silver nitrate (23). In this study, breakthrough curves (BTC) of the bacteria were drawn as output concentration (C) based on $\mathrm{CFU} / \mathrm{mL}$ and the relative bacterial concentrations versus time were recorded using Excel software.

\section{Theory and Model}

Chloride transport

The transmission of non-reactive elements, such as chloride, is generally expressed in terms of mass-flow equation. For stable flow conditions, this equation can be as follows.

$$
\frac{\partial C}{\partial t}=-\mathrm{v} \frac{\partial C}{\partial z}+D \frac{\partial^{2} C}{\partial z^{2}}
$$

Where, $\mathrm{C}$ is the salt concentration in the liquid phase $\left(\mathrm{ML}^{3}\right), \mathrm{D}$, the diffusion coefficient $\left(\mathrm{L}^{2} \mathrm{~T}^{-1}\right), \mathrm{v}$, the average pore velocity of water $\left(\mathrm{LT}^{-1}\right), \mathrm{t}$, time and $\mathrm{z}$ is depth (L). First, the sensitive parameters of chloride breakthrough curve were detected by sensitivity analysis and their values were

Table 1. The primary characteristics of the soil column test

\begin{tabular}{|c|c|c|c|c|c|}
\hline Material & $\begin{array}{l}\text { Pore volume } \\
\text { (PV) }\left(\mathrm{cm}^{3}\right)\end{array}$ & $\begin{array}{l}\text { Vapor flow velocity } \\
\qquad(\bar{v})\left(\mathrm{cm} \mathrm{h}^{-1}\right)\end{array}$ & $\begin{array}{l}\text { Stable flow rate } \\
\text { (q) }\left(\mathrm{cmh}^{-1}\right)\end{array}$ & $\begin{array}{c}\text { Volumetric soil moisture } \\
(\theta)\left(\mathrm{cm}^{3} \mathrm{~cm}^{-3}\right)\end{array}$ & Soil texture \\
\hline Macropore & 737.9 & 14.3 & 4.70 & 0.47 & Loamy sand (LS) \\
\hline Matrix & 926.3 & 18.2 & 7.04 & 0.59 & Sandy loam (SL) \\
\hline
\end{tabular}


estimated by the inverse modeling of HYDRUS-2D. The model for some hydraulic parameters of Van Genuchten equation and soil diffusion coefficients was calibrated using measured data of chlorine concentration of the drained water from the column during the experiment.

\section{Bacteria transport}

The general equation governing the absorption and transfer of bacteria in the soil was expressed by the two-site kinetic attachment-detachment model (24). This model describes the attachment-detachment processes with a first-order kinetic process. The kinetic absorption yield consists of two steps. In the first step, the so-called mass transfer, the bacteria are transferred from the liquid phase to the particle surface. In the second step, the bacteria are absorbed on the soil particle surface by the physical and chemical interactions. In a two-dimensional mode, the kinetic attachment-detachment model expresses the transfer of colloidal particles, bacteria and viruses as follows:

$$
\begin{aligned}
& \frac{\rho_{b}}{\theta} \frac{\partial S_{1}}{\partial t}=k_{a t t 1} C-k_{\operatorname{det} 1} \frac{\rho b}{\theta}-\mu_{s} \rho_{b} S_{1} \\
& \frac{\rho_{\mathrm{b}}}{\theta} \frac{\partial \mathrm{S}_{2}}{\partial \mathrm{t}}=\mathrm{k}_{\mathrm{att} 2} \mathrm{C}-\mathrm{k}_{\mathrm{det} 2} \frac{\rho \mathrm{b}}{\theta}-\mu_{\mathrm{s}} \rho_{\mathrm{b}} \mathrm{S}_{2} \\
& \frac{\partial \mathrm{C}}{\partial \mathrm{t}}+\frac{\rho_{\mathrm{b}}}{\theta} \frac{\partial \mathrm{S}_{1}}{\partial \mathrm{t}}+\frac{\rho_{\mathrm{b}}}{\theta} \frac{\partial \mathrm{S}_{2}}{\partial \mathrm{t}}=\mathrm{D} \frac{\partial^{2} \mathrm{C}}{\partial \mathrm{z}^{2}}-\mathrm{v} \frac{\partial \mathrm{C}}{\partial \mathrm{z}}-\mu_{1} \mathrm{C}-\mu_{\mathrm{s}} \rho_{\mathrm{b}}\left(\mathrm{S}_{1}+\mathrm{S}_{2}\right)
\end{aligned}
$$

where $\mathrm{C}$ is the concentration of bacteria in the liquid phase $\left(\mathrm{NL}^{-3}\right), \mathrm{S}$, the concentration (colloid, bacteria or viruses) in the solid phase, the indexes of numbers 1 and 2, indicate kinetic sites 1 and 2, respectively, $\mathrm{D}$, diffusion coefficient $\left(\mathrm{L}^{2} \mathrm{~T}^{-1}\right), v$, pore velocity of water $\left(\mathrm{LT}^{-1}\right), \theta$, total porosity $\left(\mathrm{L}^{3} \mathrm{~L}^{-3}\right), \rho_{b}$, soil bulk density $\left(\mathrm{ML}^{-3}\right), \mathrm{S}$, the concentration of bacteria adsorbed by the soil $\left(\mathrm{NL}^{-3}\right), \mathrm{K}_{\text {att }}$ the absorption rate of bacteria $\left(\mathrm{T}^{-1}\right), \mathrm{k}_{\mathrm{det}}$, the detachment rate of bacteria from soil particles $\left(\mathrm{T}^{-1}\right), t$, time, $\mu_{1}$, inactivation of the bacteria in the liquid phase and $\mu_{\mathrm{s}}$, inactivation of the bacteria in the solid phase. According to the sensitivity analysis, $\mathrm{K}_{\text {att }}$ and $\mathrm{k}_{\mathrm{det}}$ parameters were used for calibration.

\section{Results}

Transfer of chloride

The measured BTCs of chloride and the model fits with the HYDRUS-2D are demonstrated in Figure 1. The ascending line of the chloride breakthrough curve has a steep slope, therefore, chloride is rapidly observed in the drained water.

The optimal calibration parameters by HYDRUS-2D model are presented in Table 2. The residual moisture

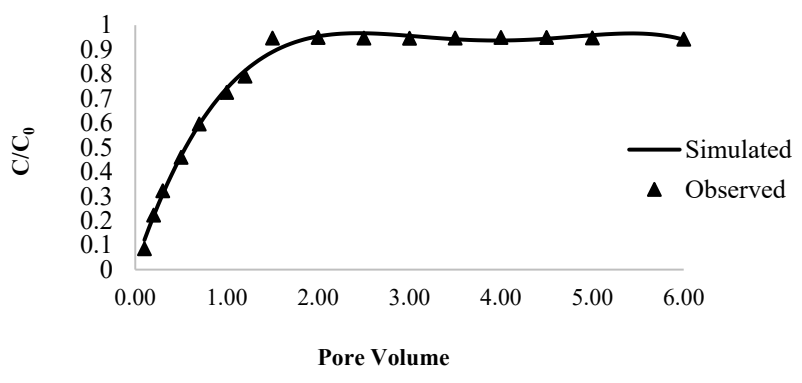

Figure 1. The measured chloride breakthrough curve (solid triangle) fitted with the HYDRUS-2D model (continuous line).

content (0.67) and saturated moisture content (0.5) in the matrix were greater than macropores. The saturation hydraulic conductivity in macropores was higher than the matrix $\left(0.241 \mathrm{cmh}^{-1}\right)$. DIFW, DISPT, DISPL parameters in both matrix and macro phases had constant values.

\section{Transfer of bacteria}

Estimated parameters of kinetic attachment-detachment model of bacteria by HYDRUS-2D are presented in Table 3. The results showed that soil column treatments with a pore diameter of 1 and $2 \mathrm{~cm}$ had a lower attachment coefficient than the saturated column without macropores diameter. This attachment rate was observed in both attachment sites. Therefore, by increasing the diameter of macropore, more conditions were provided for the transmission of the bacteria and its lower attachment. As shown in Table 3, $\mathrm{K}_{\text {att }}$ value was 10 times more than $\mathrm{k}_{\text {det }}$, indicating that the attachment of the bacteria in the saturated columns was almost irreversible. Two-site attachment parameters show that soil columns had two kinetic attachment sites (Table 3). The kinetic attachment site 1 was related to the salts with the same charge, such as sodium chloride, in which attachment process was very rapid and detachment was very slow. The attachment rate of the bacteria in the kinetic site 1 in the soil column was between 0.0015 and 0.0065 while the rate of detachment was zero in this site. However, in the attachment site 2, two processes of attachment and detachment were rapid. The attachment rate of bacteria in site 2 varied from 0.012 to 0.062 and the detachment rate ranged from 0.0042 to 0.0053 .

The results showed that the effect of water salinity of 1 $\mathrm{dsm}^{-1}$ (the lowest salinity) on the concentration of the bacteria collected from the soil columns at the beginning of leaching, was the same (Figure 2). However, by increasing the leaching rate, the concentration of $E$. coli in the drained water collected from the soil columns was

Table 2. Values of the parameters obtained from chloride transfer in reverse modeling in two matrix and macro phases

\begin{tabular}{lllllll}
\hline Parameter & $\boldsymbol{\theta}_{\mathbf{r}}$ & $\boldsymbol{\theta}_{\mathrm{s}}$ & $\mathbf{K}_{\mathrm{s}}\left(\mathbf{c m h}^{-1}\right)$ & DIFW $\left(\mathbf{c m}^{2} / \mathbf{d a y}\right)$ & DISPT $(\mathbf{c m})$ & $\mathbf{D I S P L}(\mathbf{c m})$ \\
\hline Matrix & 0.067 & 0.50 & 0.015 & 0.05 & 0.05 & 0.05 \\
Macropore & 0.057 & 0.48 & 0.241 & 0.05 & 0.05 & 0.05 \\
\hline
\end{tabular}


Table 3. The calibrated attachment-detachment model parameters of the bacteria

\begin{tabular}{|c|c|c|c|c|c|c|}
\hline Soil Columns & $\mathrm{EC}\left(\mathrm{dsm}^{-1}\right)$ & Macrospore Diameter (cm) & $\mathrm{K}_{\mathrm{att1}}$ & $\mathbf{K}_{\text {det1 }}$ & $\mathrm{K}_{\mathrm{att2}}$ & $\mathbf{K}_{\mathrm{det} 2}$ \\
\hline$A$ & 1 & 0 & 0.0065 & 0 & 0.0051 & 0.00042 \\
\hline B & 1 & 1 & 0.0045 & 0 & 0.0052 & 0.00052 \\
\hline C & 1 & 2 & 0.0055 & 0 & 0.0062 & 0.00053 \\
\hline $\mathrm{D}$ & 2 & 0 & 0.0049 & 0 & 0.0052 & 0.00052 \\
\hline$E$ & 2 & 1 & 0.0035 & 0 & 0.0032 & 0.00055 \\
\hline $\mathrm{F}$ & 2 & 2 & 0.0035 & 0 & 0.0031 & 0.00049 \\
\hline G & 4 & 0 & 0.0025 & 0 & 0.0022 & 0.00051 \\
\hline $\mathrm{H}$ & 4 & 1 & 0.0015 & 0 & 0.0022 & 0.00048 \\
\hline 1 & 4 & 2 & 0.0021 & 0 & 0.0012 & 0.00042 \\
\hline
\end{tabular}

decreased.

The results of the evaluation of the simulated breakthrough curve showed that although the fitted data in the simulated breakthrough curve did not overlap with the measured values and there was an over-estimation in the simulation results, but the model was able to simulate the observed data well (Figure 3). The results showed that the optimized attachment parameters of the model were less than the values determined in the laboratory. This suggests that the model, with no consideration for the flow in the coarse pores of the soil, greatly reduces the amount of attachment parameters to simulate the movement of the bacteria in the soil. The measured breakthrough curves of the bacteria show that the concentration of bacteria in the

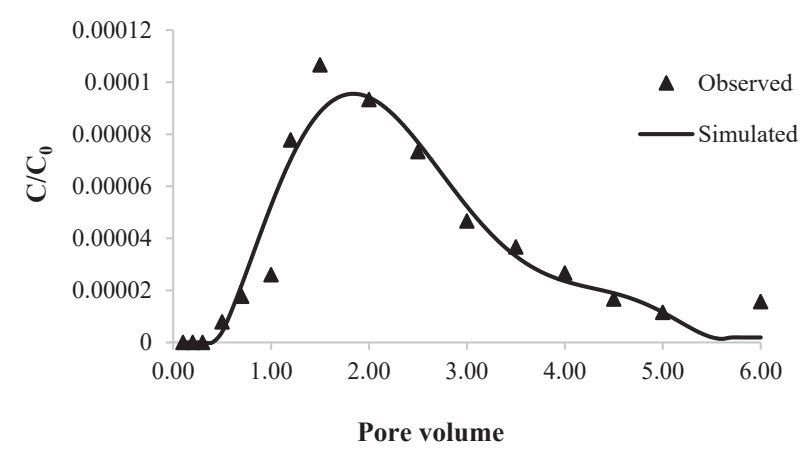

Figure 2. The measured breakthrough curve of the bacteria (solid triangle) and the calibrated breakthrough curve of the bacteria (continuous line) with HYDRUS-2D model.

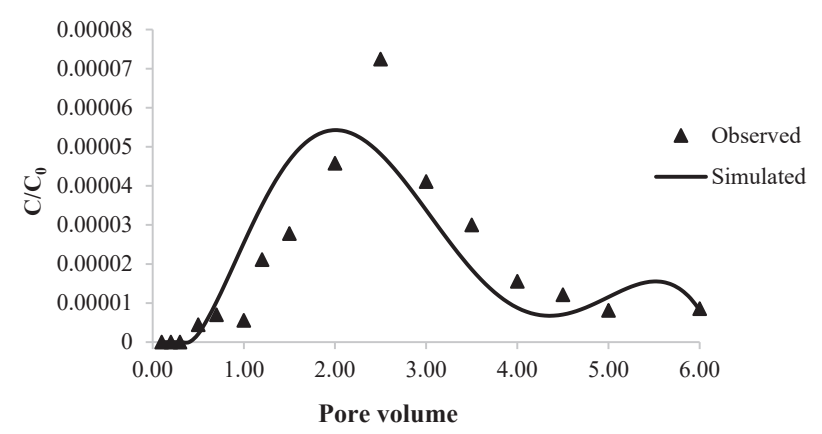

Figure 3. The measured breakthrough curve of the bacteria (solid triangle) and the simulated breakthrough curve of the bacteria (continuous line) with HYDRUS-2D model. drained water quickly reached peak concentration, and the breakthrough curve has a large dispersion, which can be due to the presence of sites with different attachment and detachment energies in the soil (Figure 3).

Also, the comparison of the measured and estimated breakthrough curve of the bacteria with bacterial attachment-detachment models is shown in Figure 4. As shown in Figure 3, the model had a very good estimation of the breakthrough curve of the bacteria. The coefficient of determination between the measured and estimated values of the breakthrough curve of the bacteria is presented in Figure 4. The results show that the coefficient of determination between the measured values of the breakthrough curve of the bacteria curve and its estimated values was 0.95 .

Discussion

Transfer of chloride

Figure 1 shows that the presence of large pores and the presence of preferential flow in the soil columns lead to early removal of chloride in the soil column. On the other hand, these curves have relatively long-tailed distribution due to the continuous flow of chloride. The elongation of breakthrough curve shows the important role of diffusion in the transfer of chloride to these soils. In saturated conditions, the chloride front quickly reaches the bottom of the soil column due to the mass and rapid flow through

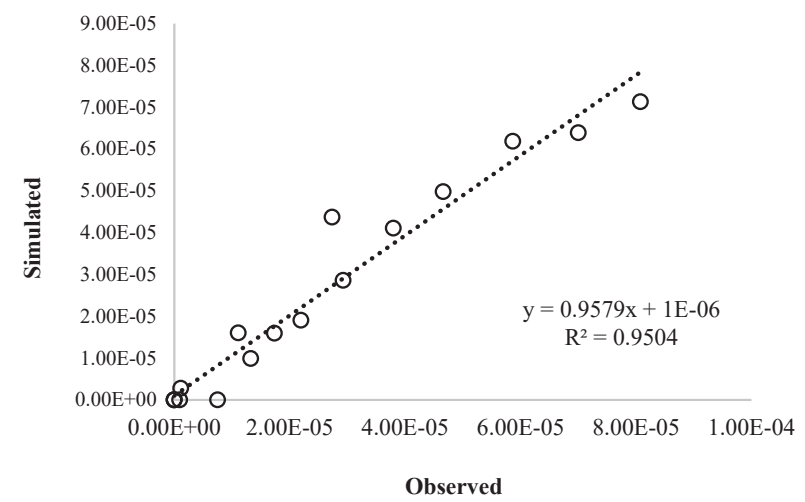

Figure 4. Comparison of the measured bacterial output with the simulated values using HYDRUS-2D model. 
the macropores. In the early stages of the experiment, up to a pore volume of 0.8 , the contamination through front piston and the preferential flow did not reached the bottom of the column and the chloride concentration in the effluent solution was negligible and close to zero. The steep slope of the curve approximately twice the pore volume can be due to the poor role of diffusion and distribution processes caused by the uniform distribution of pore size in the single-grained structure and the uniform distribution of chloride speed in saturated conditions. The superiority of the mass flow in the matrix and the preferential flow in the macropores caused the chloride to reach the bottom of the column at a very short time in $1 / 2$ of the pore volume of the drained water, and in the pore volume equal to 1 of the drained water, the relative chloride concentration can be equal to 0.5 , which represents the symmetry of the breakthrough curve. Therefore, in these conditions, delay was not observed in chloride transfer, due to the lack of interaction between the soil and chloride. Also, chloride is a passive tracer, it does not enter into exchange and precipitation reactions, and its absorption in the soil, especially in the studied soils with alkaline $\mathrm{pH}$, is very low. The curve was S-shaped and completely symmetric and has a steep slope in $\mathrm{C} / \mathrm{C} 0=0.5$, which is consistent with the results of Sebben et al (25). Their results showed that the breakthrough curve for homogeneous sandy soils and very light soils was S-shaped.

\section{Transfer of bacteria}

According to poiseuille [the poiseuille (symbol Pl) has been proposed as a derived SI unit of dynamic viscosity, named after the French physicist Jean Léonard Marie Poiseuille] rule, a large amount of the entire flow passes through the larger pores, resulting in the higher rate of bacterial transmission from the soil. Bacterial detachment is actually a risk for the return of pathogenic bacteria into the water and increases the risk of its contamination. Expressing the quantitative detachment of bacteria is necessary in determining the potential for transmission of bacteria. Field and laboratory observations showed that bacterial detachment caused the trailing of breakthrough curve to be longer (26). Jiang et al investigated several models and reported that two-attachment sites have higher performance (6).

Figure 2 shows that the salinity increased the ionic strength of the soil solution and compressed the diffused double layer (DDL). This action causes the bacteria to come closer to the surface of the soil particles and overcome the Van der Waals forces to absorb the bacteria on the surface of soil particles, therefore, with increasing solution concentration, transferring and leaching of the bacteria in the soil decreases. It seems that in lower salinity, a wider transition takes place in the preferential flow path and the arrival time is earlier. These results are consistent with the results of Liu et al (27).

As shown in Figure 3, bacterial transfer experiments have been carried out under steady state condition, the presence of fluctuations and various peak points and drops in the breakthrough curve of the bacteria and the distribution of data indicate a chemical and physical heterogeneity (28), because the soil columns were formed from different levels of salinity that have different attachment and detachment abilities. Also, it can indicate the preferential flow paths for bacterial transmission. The peak point of the breakthrough curve and also the area under the curve in the non-diameter treatment were higher and greater than that of the treatment with diameter of $1 \mathrm{~cm}$, which indicates the occurrence of preferential flow and more consumed bacteria, and as a result, the high amount of its output from the macropores, which caused the relative concentration of the bacteria reaches about 0.00001 . The peak point of the breakthrough curve in the treatment with a macropores diameter is far below the control, and these curves are relatively symmetrical in shape, indicating a lack of preferential flow in them (29). The presence of macropores results in the rapid appearance of the bacteria and the advance of the breakthrough curve shape, while the diffusion from fine pores (from the inside of the aggregate) into coarse pores leads to delays in the release of the solutes and shrinkage of the breakthrough curve shape (30). Given that the importance of the preferential flow in the transmission of bacteria, it was found that in higher ion strength, the effect of preferential flow increases even if overall bacterial transmission is reduced (10). Morales et al generally fitted two die-off and attachment/ detachment indices as a particular variable in the trailing stage, to better test the model (31). Apart from the fitting method, the attachment rate that fitted with the model was higher in sandy and loamy sandy soils than clay soils. These results are consistent with the report of Unc et al (9). They showed the preferential flows in the movement and purification of bacteria in the soil. The soil's ability to purify the bacteria in the macropores decreased (32). Wang et al showed that the numerical simulations of $E$. coli in each of the different soluble chemistry conditions were very consistent with the experimental data, except for the ability to predict some differences in the transmission between different macropore settings (18). The two-site kinetics model of HYDRUS-1D was used to predict the transfer and attachment of bacteria in the soil column. The results showed that the two-site kinetics attachmentdetachment model in comparison with the one-site model had better fitting with the data obtained from the bacterial transfer (21).

\section{Conclusion}

With regards to that the presence of oscillations and peak points and very high drop in the breakthrough curve of the bacteria in the studied soils, it was indicated that there are different attachment sites with different attachment and detachment energies. The rate of bacterial detachment in the soil columns was very low, which could indicate the role 
of salinity (sodium chloride) in the irreversible bacterial attachment. Therefore, the presence of salinity can be a significant factor in the inactivation and attachment of bacteria. It seems that the attachment of E. coli into the soil decreased with increasing salinity levels, which was due to increased competition for attachment sites. On the other hand, the preferential flows in the bacterial transmission can reduce the effect of tissue and soil attachment sites on the bacterial transmission process. The obtained results showed the effectiveness of preferential flows in different aspects of the study. It seems that in the inverse method, the attachment and detachment coefficients of the bacteria on the surface of the soil colloids were introduced into the model during the simulation process and the simulation was performed based on the attachment and detachment capacity of the bacteria. From the practical point of view, it can be concluded that when the soil is irrigated with saline water, the bacteria are exposed to preferential flows from the seams and gaps due to the contraction and expansion and are easily transmitted. But as time passes, the bacteria are disappeared through the transfer path due to high salinity and accumulate on the surface of the soil. Although the bacterial transmission is facilitated in salinity, the results of this study showed that increased ionic strength of the soil solution increased the rate of bacterial purification that could be effective in controlling groundwater contamination with saline water management, so that the least transition was taken place and the conditions for the use of unconventional water sources were also created, without the environmental problem threatening the risk of groundwater pollution.

\section{Acknowledgments}

This study was extracted from a Ph.D.'s thesis conducted at Guilan University of Medical Sciences, Rasht, Iran. The authors would like to gratitude Gorgan University of Agricultural Sciences and Natural Resources for its financial support and all others who involved improvement of this study.

\section{Ethical issues}

The author hereby certifies that all data collected during the study is as stated in the manuscript, and no data from the study has been or will be published separately elsewhere.

\section{Competing interests}

The author declares that he has no competing interests.

\section{Authors' contributions}

The author contributed and was involved in the suggestion of the problem, design of experiments, data collection, analysis, and interpretation, and article approval.

\section{References}

1. Jackwood RW. Predicting fate and transport of fecal bacteria through soils using an advection-dispersion model. The University of Toledo; 2013.

2. Kadam AM, Oza GH, Nemade PD, Shankar HS. Pathogen removal from municipal wastewater in constructed soil filter. Ecol Eng 2008; 33(1): 37-44. doi: 10.1016/j. ecoleng.2007.12.001.

3. Cey EE, Rudolph DL, Passmore J. Influence of macroporosity on preferential solute and colloid transport in unsaturated field soils. J Contam Hydrol 2009; 107(1-2): 45-57. doi: 10.1016/j.jconhyd.2009.03.004.

4. Darnault CJG, Steenhuis TS, Garnier P, Kim YJ, Jenkins $\mathrm{MB}$, Ghiorse WC, et al. Preferential flow and transport of Cryptosporidium parvum oocysts through the Vadose Zone: experiments and modeling. Vadose Zone J 2004; 3(1): 262-70. doi: 10.2136/vzj2004.2620.

5. Guber AK, Shelton DR, Pachepsky YA. Transport and Retention of Manure-Borne Coliforms in Soil. Vadose Zone J 2005; 4(3): 828-37. doi: 10.2136/vzj2004.0097.

6. Jiang S, Pang L, Buchan GD, Simunek J, Noonan MJ, Close ME. Modeling water flow and bacterial transport in undisturbed lysimeters under irrigations of dairy shed effluent and water using HYDRUS-1D. Water Res 2010; 44(4): 1050-61. doi: 10.1016/j.watres.2009.08.039.

7. Pang L, McLeod M, Aislabie J, Simunek J, Close M, Hector R. Modeling transport of microbes in ten undisturbed soils under effluent irrigation. Vadose Zone J 2008; 7(1): 97-111. doi: 10.2136/vzj2007.0108.

8. Pivetz BE, Steenhuis TS, Kelsey JW, Alexander M. A procedure to calculate biodegradation during preferential flow through heterogeneous soil columns. Soil Sci Soc Am J 1996; 60(2): 381-8. doi: 10.2136/sssaj1996.036159950060 00020008x.

9. Unc A, Goss MJ. Movement of faecal bacteria through the Vadose Zone. Water Air Soil Pollut 2003; 149(1-4): 327-37. doi: 10.1023/a:1025693109248.

10. Wang Y, Bradford SA, Simunek J. Transport and fate of microorganisms in soils with preferential flow under different solution chemistry conditions. Water Resour Res 2013; 49(5): 2424-36. doi: 10.1002/wrcr.20174.

11. Gargiulo G, Bradford SA, Simunek J, Ustohal P, Vereecken $\mathrm{H}$, Klumpp E. Bacteria transport and deposition under unsaturated flow conditions: The role of water content and bacteria surface hydrophobicity. Vadose Zone J 2008; 7(2): 406-19. doi: 10.2136/vzj2007.0068.

12. Tufenkji N. Modeling microbial transport in porous media: Traditional approaches and recent developments. Adv Water Resour 2007; 30(6-7): 1455-69. doi: 10.1016/j. advwatres.2006.05.014.

13. Foppen JW, van Herwerden M, Schijven J. Measuring and modelling straining of Escherichia coli in saturated porous media. J Contam Hydrol 2007; 93(1-4): 236-54. doi: 10.1016/j.jconhyd.2007.03.001.

14. Feng G, Zhang Z, Wan C, Lu P, Bakour A. Effects of saline water irrigation on soil salinity and yield of summer maize (Zea mays L.) in subsurface drainage system. Agric Water Manag 2017; 193: 205-13. doi: 10.1016/j.agwat.2017.07.026.

15. Mamilov A, Dilly OM, Mamilov S, Inubushi K. Microbial eco-physiology of degrading aral sea wetlands: Consequences for C-cycling. J Soil Sci Plant Nutr 2004; 50(6): 839-42. doi: 10.1080/00380768.2004.10408544. 16. Kim KR, Owens G, Naidu R. Heavy metal distribution, 
bioaccessibility, and phytoavailability in long-term contaminated soils from Lake Macquarie, Australia. Soil Research 2009; 47(2): 166-76. doi: 10.1071/SR08054.

17. Foppen JW, Schijven JF. Evaluation of data from the literature on the transport and survival of Escherichia coli and thermotolerant coliforms in aquifers under saturated conditions. Water Res 2006; 40(3): 401-26. doi: 10.1016/j. watres.2005.11.018.

18. Wang Y, Bradford SA, Simunek J. Physicochemical factors influencing the preferential transport of escherichia coli in soils. Vadose Zone J 2014; 13(1):1-10. doi: 10.2136/ vzj2013.07.0120.

19. Mohammadi AA, Ghaderpoori M, Yousefi M, Rahmatipoor M, Javan S. Prediction and modeling of fluoride concentrations in groundwater resources using an artificial neural network: a case study in Khaf. Environ Health Eng Manag J 2016; 3(4): 217-24. doi: 10.15171/ehem.2016.23.

20. Simunek J, van Genuchten MT, Sejna M. The HYDRUS2D Software Package for Simulating the Two-dimensional Movement of Water, Heat, and Multiple Solutes in Variablysaturated Media: Version 2.0. Colorado School of Mines; 1999. doi: 10.17221/1200-swr.

21. Safadost A, Mahbubi AA, Mossadeghi MR, Khodkaramian G, Heydari A. Transport of Escherichia coli in soil columns under different temperature and flow conditions. Water and Soil Science 2011; 15(57):183-97. [In Persian].

22. Mahon CR, Lehman DC, Manuselis G. Textbook of Diagnostic Microbiology. Elsevier Health Sciences; 2014. doi: $\quad 10.1016 / 0732-8893(85) 90044-6$.

23. Vogel AI. A Text-Book Of Quantitative Inorganic AnalysisTheory And Practice. 2nd ed. London: Longmans; 2013.

24. Schijven JF, Simunek J. Kinetic modeling of virus transport at the field scale. J Contam Hydrol 2002; 55(1-2): 113-35. doi: 10.1016/S0169-7722(01)00188-7.
25. Sebben ML, Werner AD. A modelling investigation of solute transport in permeable porous media containing a discrete preferential flow feature. Adv Water Resour 2016; 94: 307-17. doi: 10.1016/j.advwatres.2016.05.022.

26. United States Department of Agriculture. Soil taxonomy: A basic system of soil classification for making and interpreting soil surveys. Soil Science 1977; 123(4): 270. doi: 10.1097/00010694-197704000-00011.

27. Liu X, Gao C, Ji D, Walker SL, Huang Q, Cai P. Survival of Escherichia coli O157:H7 in various soil particles: importance of the attached bacterial phenotype. Biol Fertil Soils 2017; 53(2): 209-19. doi: 10.1007/s00374-016-1172-y.

28. Pang L, Simunek J. Evaluation of bacteria-facilitated cadmium transport in gravel columns using the HYDRUS colloid-facilitated solute transport model. Water Resour Res 2006; 42(12). doi: 10.1029/2006WR004896.

29. Li B, Pales AR, Clifford HM, Kupis S, Hennessy S, Liang $\mathrm{W}-\mathrm{Z}$, et al. Preferential flow in the vadose zone and interface dynamics: Impact of microbial exudates. J Hydrol 2018; 558: 72-89. doi: 10.1016/j.jhydrol.2017.12.065.

30. Liu HF, Genard M, Guichard S, Bertin N. Model-assisted analysis of tomato fruit growth in relation to carbon and water fluxes. J Exp Bot 2007; 58(13): 3567-80. doi: 10.1093/ jxb/erm202.

31. Morales I, Atoyan JA, Amador JA, Boving T. Transport of pathogen surrogates in soil treatment units: Numerical modeling. Water 2014; 6(4): 818-38. doi: 10.3390/w6040818.

32. Sahraei N, Mahboobi AA. Investigating the Effect of Soil and Organic Fertilizer Building on the Movement of Escherichia coli in Soil Columns. Twelfth National Conference on the Health of Iran; 2009 Nov 3-5; Shahid Beheshti University of Medical Sciences, Tehran; 2009. [In Persian]. 